\title{
Endothelial Nitric Oxide Synthase (eNOS) 4b/a Gene Polymorphisms and Coronary Artery Disease: Evidence from a Meta-Analysis
}

\author{
Yujiao Yang ${ }^{\dagger}$, Kang Du ${ }^{\dagger}$, Zhengxia Liu and Xiang Lu * \\ Department of Geriatrics, the Second Affiliated Hospital, Nanjing Medical University, \\ Nanjing 210029, Jiangsu, China; E-Mails: yangyujiao626@126.com (Y.Y.); \\ dukang@njmu.edu.cn (K.D.); liuzx0503@gmail.com (Z.L.) \\ $\dagger$ These authors contributed equally to this work. \\ * Author to whom correspondence should be addressed; E-Mail: luxiang66@njmu.edu.cn; \\ Tel.: +86-25-5880-2883; Fax: +86-25-5850-9994.
}

Received: 25 March 2014; in revised form: 24 April 2014 / Accepted: 29 April 2014 / Published: 7 May 2014

\begin{abstract}
A variety of studies have suggested that the $4 \mathrm{~b} / \mathrm{a}$ polymorphism in the endothelial nitric oxide synthase (eNOS) was associated with coronary artery disease (CAD) risk. However, the data remain conflicting. The aim of the present meta-analysis was to estimate the overall association between risk of CAD and eNOS 4b/a polymorphism. Case-control, cohort or cross-sectional studies evaluating the association between eNOS $4 b / a$ polymorphism and CAD susceptibility were systematically identified in PubMed up to 31 October 2013. Pooled odds ratios (OR) and corresponding 95\% confidence intervals (CIs) were calculated to assess the association in overall and subgroup analyses. A total of 10,617 cases and 8302 controls from 37 studies were included in the study. The results of overall analysis revealed significant positive associations between CAD risk and eNOS $4 b / a$ polymorphism in homozygote comparisons ( $\mathrm{OR}=1.47,95 \% \mathrm{CI}=1.16-1.87)$, heterozygote comparisons $(\mathrm{OR}=1.14,95 \% \mathrm{CI}=1.02-1.27)$ and dominant models $(\mathrm{OR}=1.18,95 \% \mathrm{CI}=1.06-1.33)$. In subgroup analyses, similar associations were identified in African individuals, as determined using population-based source subgroups and noted in small-and-moderate sample size subgroups (case sample size or control sample size <500). The current meta-analysis revealed that eNOS $4 \mathrm{~b} / \mathrm{a}$ polymorphisms could be a risk factor for developing $\mathrm{CAD}$, particularly in African populations and population-based subgroups.
\end{abstract}


Keywords: endothelial nitric oxide synthase (eNOS); coronary artery disease (CAD); polymorphism; meta-analysis

\section{Introduction}

Coronary artery disease (CAD) also known as coronary heart disease (CHD), is the leading cause of death and disability worldwide [1,2]. CAD is associated with genetic and environmental factors, as well as their interactions [3]. Confirmed risk factors for CAD include hypercholesterolemia, hypertension, smoking, and diabetes [4]. However, in addition to modifiable risk factors, genetic factors can also predispose individuals to CAD. It has been estimated that genetic risk factors explain approximately $20 \%-60 \%$ of CAD cases [5].

Nitric oxide (NO) is an important atheroprotective mediator that helps mediate endothelium-dependent vasodilatation. Abnormalities in NO generation could play an important role in the pathophysiology of CAD [6]. NO is synthesized from L-arginine by the action of nitric oxide synthase (NOS). There are at least three isoenzymes of NOS: inducible NOS, neuronal NOS, and endothelial NOS (eNOS) [7]. The eNOS gene is located on chromosome 7q35-q36 and is sized 21 kilobases $(\mathrm{kb})$ [8]. A number of studies have suggested that polymorphisms in the eNOS gene affected NO availability and were associated with CAD morbidity. One of the most clinically relevant eNOS variants forms 27-basepair (bp) tandem repeats in intron $4(4 b / a)$. The eNOS $4 b$ allele contains five repeats of the 27 bp sequence, whereas eNOS $4 a$, which is the rare allele, carries a deletion of one of the first three of these repeats [9].

The association between eNOS $4 b / a$ gene polymorphisms and CAD remains controversial, and the results of two previous meta-analyses were inconsistent [10,11]. In 2004, Casas et al. performed a meta-analysis of 16 studies and found an increased risk of ischemic heart disease (IHD) in individuals carrying the homozygous a allele compared with the $b$ allele [10]. However, a subsequent meta-analysis in 2010 reported conflicting data, where eNOS 4b/a did not significantly increase the risk of developing CAD [11]. A large number of new case-control studies assessing the association between eNOS $4 b / a$ polymorphisms and the CAD risk have been published since 2010. Therefore, we performed a meta-analysis using a more complete database to clarify the association between eNOS $4 \mathrm{~b} / \mathrm{a}$ polymorphisms and CAD risk.

\section{Results and Discussion}

\subsection{Characteristics of Included Studies}

A total of 373 papers were initially identified during the literature search and from other sources; 37 of these met the inclusion criteria for this analysis [9,12-47]. A flow chart describing the literature search and study identification is shown in Figure 1. The meta-analysis of the $4 b / a$ polymorphism included 10,617 CAD cases and 8302 controls. The study characteristics are summarized in Table 1 . The number of subjects in the studies varied considerably (range from 40 to 1265 in the case group and from 34 to 620 in the control group). Among the 37 case-control studies, 11 studies included Asian population [15-25], and 26 assessed non-Asians [9,12-14,26-47]. Controls were mainly matched in 
terms of gender and age. Fourteen studies were hospital-based [16-18,20,21,25,28,37-40,42,43,45], and 20 were population-based $[9,12-15,19,22,23,26,27,29-34,36,41,46,47]$. Thirty studies were performed using $<500$ subjects in the case group [12-27,29,33-36,38-47] and 33 were conducted with $<500$ subjects in the control group [9,12-15,17-29,32,34-47]. Furthermore, there were 20 studies of CAD [9,18,20,22,23,25,29,30,32,34-40,42-44,46], four of CHD [17,26-28], three of acute myocardial infarction $[15,19,45]$, six of myocardial infarction (MI) [12-14,16,31,41], and four of acute coronary syndrome $[21,24,33,47]$.

Figure 1. Flow diagram of study identification.

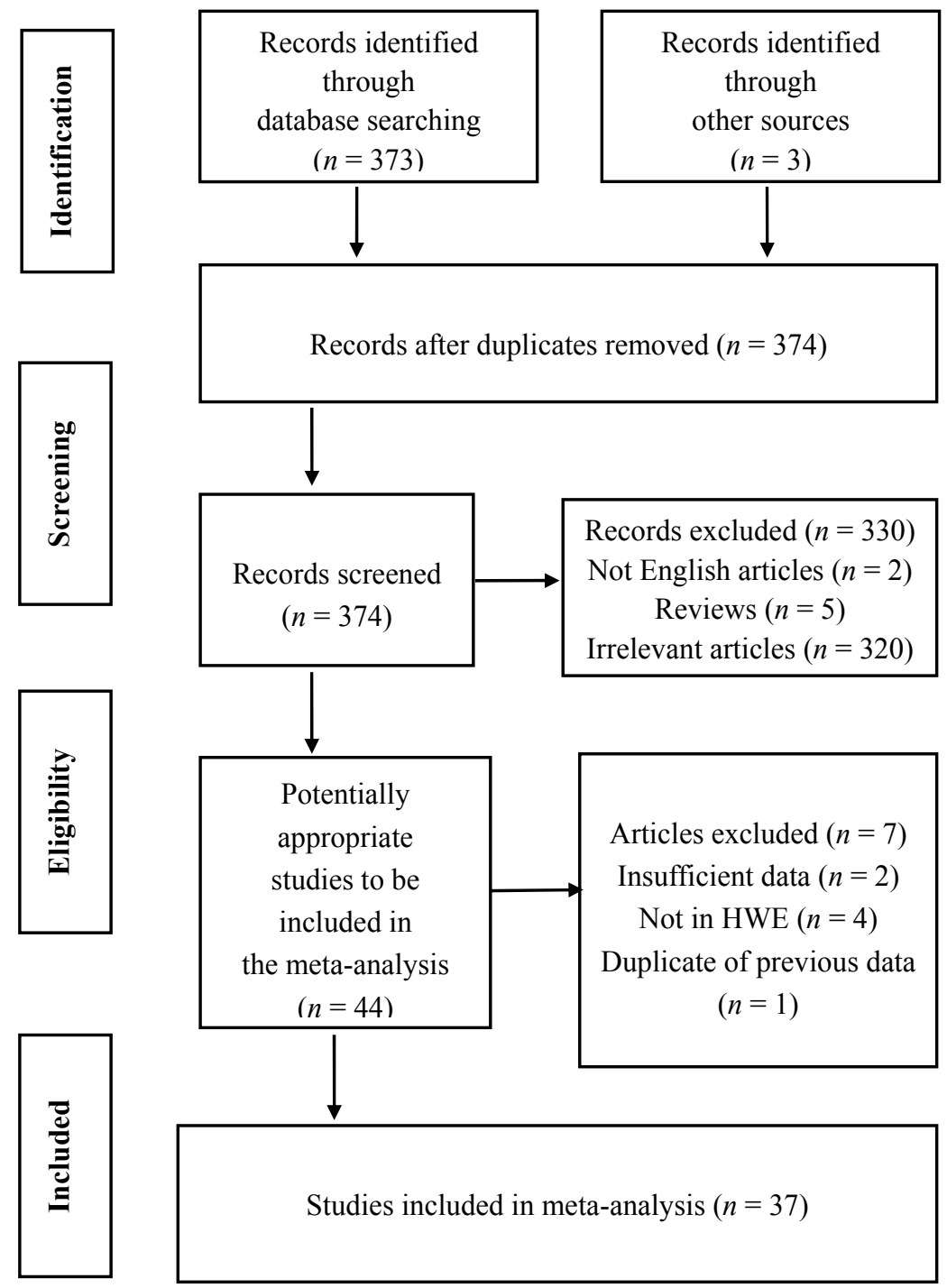

\subsection{Meta-Analysis Results}

The relationship between eNOS $4 b / a$ polymorphisms and CAD risk are summarized in Table 2 . Overall, significant positive associations between CAD risk and eNOS 4b/a polymorphism were identified in the homozygote comparison ( $\left.a a v s . b b, \mathrm{OR}=1.47,95 \% \mathrm{CI}=1.16-1.87, p_{\text {heterogeneity }}=0.085\right)$, the heterozygote comparison ( $\left.a b v s . b b, \mathrm{OR}=1.14,95 \% \mathrm{CI}=1.02-1.27, p_{\text {heterogeneity }}<0.001\right)$ and the dominant model $\left(a b+a a\right.$ vs. $b b, \mathrm{OR}=1.18,95 \% \mathrm{CI}=1.06-1.33$, $\left.p_{\text {heterogeneity }}<0.001\right)$. 
Table 1. Study Characteristics of genotypes in coronary artery disease (CAD) cases and controls in the analysis of endothelial nitric oxide synthase (eNOS) 4b/a polymorphism.

\begin{tabular}{|c|c|c|c|c|c|c|c|c|c|c|c|c|c|}
\hline \multirow{3}{*}{ Author } & \multirow{3}{*}{ Year } & \multirow{3}{*}{ Country } & \multirow{3}{*}{ Ethnicity } & \multirow{3}{*}{$\begin{array}{l}\text { Source of } \\
\text { controls }\end{array}$} & \multirow{3}{*}{ End points } & \multirow{2}{*}{\multicolumn{2}{|c|}{ Sample size }} & \multicolumn{6}{|c|}{ Genotype distribution } \\
\hline & & & & & & & & \multicolumn{3}{|c|}{ Control } & \multicolumn{3}{|c|}{ Case } \\
\hline & & & & & & Control & Case & $a a$ & $a b$ & $b \boldsymbol{b}$ & $a a$ & $a b$ & $\boldsymbol{b} \boldsymbol{b}$ \\
\hline Wang et al. & 1996 & Australia & Caucasian & PB & CAD & 153 & 549 & 1 & 50 & 102 & 18 & 122 & 409 \\
\hline Hibi et al. & 1998 & Japan & Asian & PB & AMI & 357 & 226 & 5 & 68 & 284 & 4 & 48 & 174 \\
\hline Ichihara et al. & 1998 & Japan & Asian & HB & MI & 550 & 455 & 7 & 97 & 446 & 9 & 107 & 339 \\
\hline Odawara et al. & 1998 & Japan & Asian & HB & CHD & 122 & 42 & 0 & 19 & 103 & 0 & 11 & 31 \\
\hline Hooper et al. & 1999 & American & African & PB & MI & 185 & 110 & 15 & 68 & 102 & 14 & 52 & 44 \\
\hline Nakagami et al. & 1999 & Japan & Asian & $\mathrm{HB}$ & CAD & 34 & 40 & 1 & 9 & 24 & 1 & 18 & 21 \\
\hline Park et al. & 2000 & Korea & Asian & PB & AMI & 206 & 121 & 1 & 49 & 156 & 5 & 23 & 93 \\
\hline Fowkes et al. & 2000 & UK & Caucasian & PB & CHD & 300 & 137 & 5 & 64 & 231 & 4 & 37 & 96 \\
\hline Pulkkinen et al. & 2000 & Finland & Caucasian & PB & CHD & 110 & 308 & 5 & 26 & 79 & 9 & 96 & 203 \\
\hline Sigusch et al. & 2000 & Germany & Caucasian & $\mathrm{HB}$ & CHD & 413 & 625 & 11 & 115 & 287 & 12 & 159 & 454 \\
\hline Granath et al. & 2001 & Australia & Caucasian & PB & CAD & 620 & 567 & 14 & 158 & 448 & 11 & 138 & 418 \\
\hline Alvarez et al. & 2001 & Spain & Caucasian & PB & CAD & 300 & 170 & 6 & 72 & 222 & 2 & 37 & 131 \\
\hline Hwang et al. & 2002 & Taiwan & Asian & $\mathrm{HB}$ & CAD & 70 & 149 & 0 & 14 & 56 & 1 & 32 & 116 \\
\hline Gardemann et al. & 2002 & Germany & Caucasian & PB & MI & 528 & 1265 & 13 & 144 & 371 & 25 & 306 & 934 \\
\hline Cine et al. & 2002 & Turkey & other & PB & MI & 306 & 207 & 2 & 55 & 249 & 9 & 55 & 143 \\
\hline Park et al. & 2004 & Korea & Asian & HB & ACS & 142 & 164 & 7 & 30 & 105 & 4 & 21 & 139 \\
\hline Agema et al. & 2004 & Netherlands & Caucasian & PB & CAD & 466 & 752 & 8 & 77 & 381 & 12 & 195 & 545 \\
\hline Letonja et al. & 2004 & Slovenia & Caucasian & PB & CAD & 109 & 151 & 6 & 30 & 73 & 6 & 41 & 104 \\
\hline Fatini et al. & 2004 & Italy & Caucasian & PB & ACS & 537 & 477 & 14 & 138 & 385 & 24 & 138 & 315 \\
\hline Milutinovic et al. & 2005 & Slovenia & Caucasian & NM & CAD & 188 & 215 & 10 & 58 & 120 & 11 & 60 & 144 \\
\hline Rao et al. & 2005 & America & $\begin{array}{c}\text { Caucasia }+ \\
\text { African }\end{array}$ & $\mathrm{HB}$ & CAD & 50 & 144 & 1 & 17 & 32 & 6 & 40 & 98 \\
\hline Matyar et al. & 2005 & Turkey & other & $\mathrm{HB}$ & CAD & 133 & 133 & 1 & 35 & 97 & 5 & 47 & 81 \\
\hline Salimi et al. & 2006 & Iran & other & NM & CAD & 158 & 141 & 1 & 29 & 128 & 3 & 41 & 97 \\
\hline
\end{tabular}


Table 1. Cont.

\begin{tabular}{|c|c|c|c|c|c|c|c|c|c|c|c|c|c|}
\hline \multirow{3}{*}{ Author } & \multirow{3}{*}{ Year } & \multirow{3}{*}{ Country } & \multirow{3}{*}{ Ethnicity } & \multirow{3}{*}{$\begin{array}{c}\text { Source of } \\
\text { controls }\end{array}$} & \multirow{3}{*}{ End points } & \multirow{2}{*}{\multicolumn{2}{|c|}{ Sample size }} & \multicolumn{6}{|c|}{ Genotype distribution } \\
\hline & & & & & & & & \multicolumn{3}{|c|}{ Control } & \multicolumn{3}{|c|}{ Case } \\
\hline & & & & & & Control & Case & $a a$ & $a b$ & $b \boldsymbol{b}$ & $a a$ & $a b$ & $b \boldsymbol{b}$ \\
\hline Agirbasli et al. & 2006 & Turkey & other & HB & CAD & 100 & 100 & 0 & 21 & 79 & 4 & 21 & 75 \\
\hline Kim et al. & 2007 & Korea & Asian & $\mathrm{PB}$ & CAD & 211 & 147 & 0 & 40 & 171 & 2 & 35 & 110 \\
\hline Rios et al. & 2007 & Brazil & $\begin{array}{c}\text { Caucasia }+ \\
\text { African }\end{array}$ & HB & CAD & 267 & 323 & 12 & 90 & 165 & 18 & 101 & 204 \\
\hline Sampaio et al. & 2007 & Brazil & other & $\mathrm{HB}$ & AMI & 103 & 115 & 4 & 32 & 67 & 4 & 29 & 82 \\
\hline Vasilakou et al. & 2008 & Greece & Caucasian & $\mathrm{PB}$ & CAD & 161 & 209 & 5 & 39 & 117 & 9 & 60 & 140 \\
\hline Meluzin et al. & 2009 & Czech rep & Caucasian & $\mathrm{HB}$ & CAD & 89 & 321 & 0 & 26 & 63 & 10 & 103 & 208 \\
\hline Kincl et al. & 2009 & Czech rep & Caucasian & $\mathrm{HB}$ & CAD & 222 & 939 & 9 & 63 & 150 & 35 & 272 & 632 \\
\hline Bae et al. & 2010 & Korea & Asian & $\mathrm{PB}$ & CAD & 196 & 192 & 0 & 35 & 161 & 2 & 42 & 148 \\
\hline Gururajan et al. & 2010 & India & Asian & NM & ACS & 100 & 106 & 4 & 19 & 77 & 12 & 36 & 58 \\
\hline Jaramillo et al. & 2010 & Chile & other & $\mathrm{PB}$ & CAD & 112 & 112 & 1 & 16 & 95 & 3 & 12 & 97 \\
\hline Jemaaa et al. & 2012 & Tunisia & African & $\mathrm{PB}$ & MI & 250 & 310 & 4 & 61 & 185 & 15 & 105 & 190 \\
\hline Da Costa Escobar Piccoli et al. & 2012 & Brazil & other & PB & ACS & 108 & 132 & 6 & 34 & 68 & 14 & 31 & 87 \\
\hline Kallel et al. & 2013 & Tunisia & African & PB & MI & 225 & 303 & 3 & 58 & 164 & 15 & 101 & 187 \\
\hline Narne et al. & 2013 & India & Asian & $\mathrm{HB}$ & $\mathrm{CAD}$ & 121 & 160 & 2 & 42 & 77 & 5 & 50 & 105 \\
\hline
\end{tabular}

Abbreviations: eNOS, endothelial nitric oxide synthase; HB, hospital-based; PB, population-based; NM, not mentioned; OR, odds ratios; CI, confidence intervals;

CAD, coronary artery disease; CHD, coronary heart disease; MI, myocardial infarction; AMI, acute myocardial infarction; and ACS, acute coronary syndrome.

Table 2. Pooled odds ratios (OR) and 95\% confidence intervals (CI) of the association between $e N O S 4 b / a$ polymorphism and CAD.

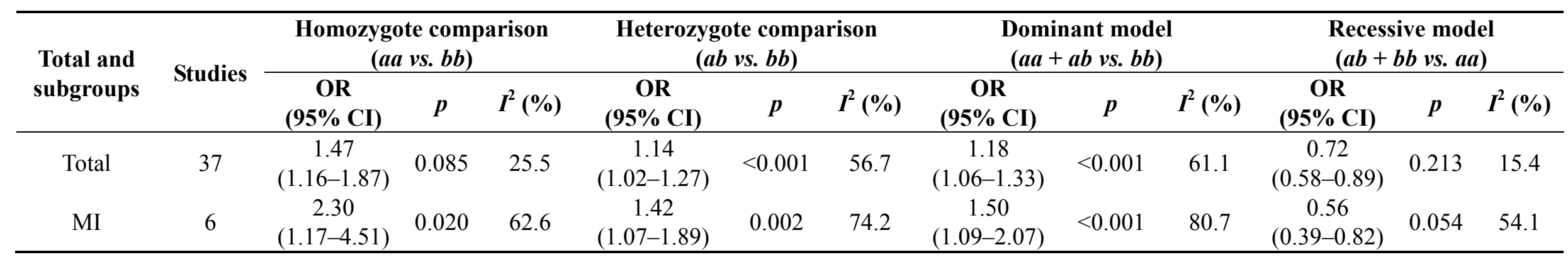


Table 2. Cont.

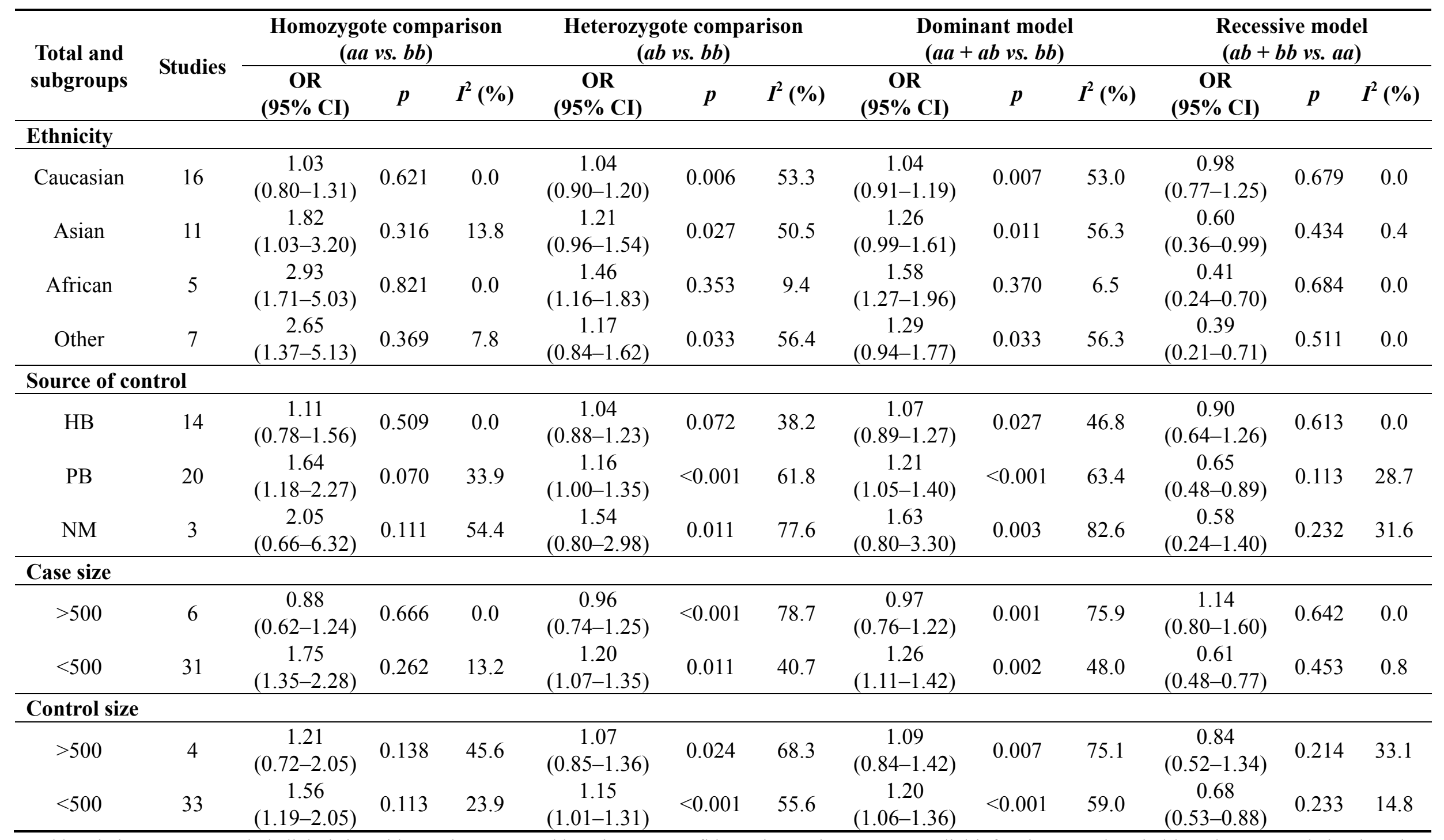

Abbreviations: eNOS, endothelial nitric oxide synthase; OR, odds ratios; CI, confidence intervals; MI, myocardial infarction; HB, hospital-based; PB, population-based; and NM, not mentioned. 
In a stratified analysis by the source of the control population, significantly increased CAD risk was detected in the population-based subgroup of all the three genetic models $(\mathrm{OR}=1.64$, $95 \% \mathrm{CI}=1.18-2.27, p=0.070$ for the homozygote comparison; $\mathrm{OR}=1.16,95 \% \mathrm{CI}=1.00-1.35$, $p<0.001$ for the heterozygote comparison; and $\mathrm{OR}=1.21,95 \% \mathrm{CI}=1.05-1.40, p<0.001$ for the dominant model). There was no significantly increased CAD risk in the hospital-based subgroup $(\mathrm{OR}=1.11,95 \% \mathrm{CI}=0.78-1.56, p=0.509$ for the homozygote comparison; $\mathrm{OR}=1.04$, $95 \% \mathrm{CI}=0.88-1.23, p=0.072$ for the heterozygote comparison; and $\mathrm{OR}=1.07,95 \% \mathrm{CI}=0.89-1.27$, $p=0.027$ in the dominant model) (Figure 2).

Figure 2. Forest plot of CAD risk associated with the eNOS $4 b / a$ polymorphism by source of control (homozygote comparison).

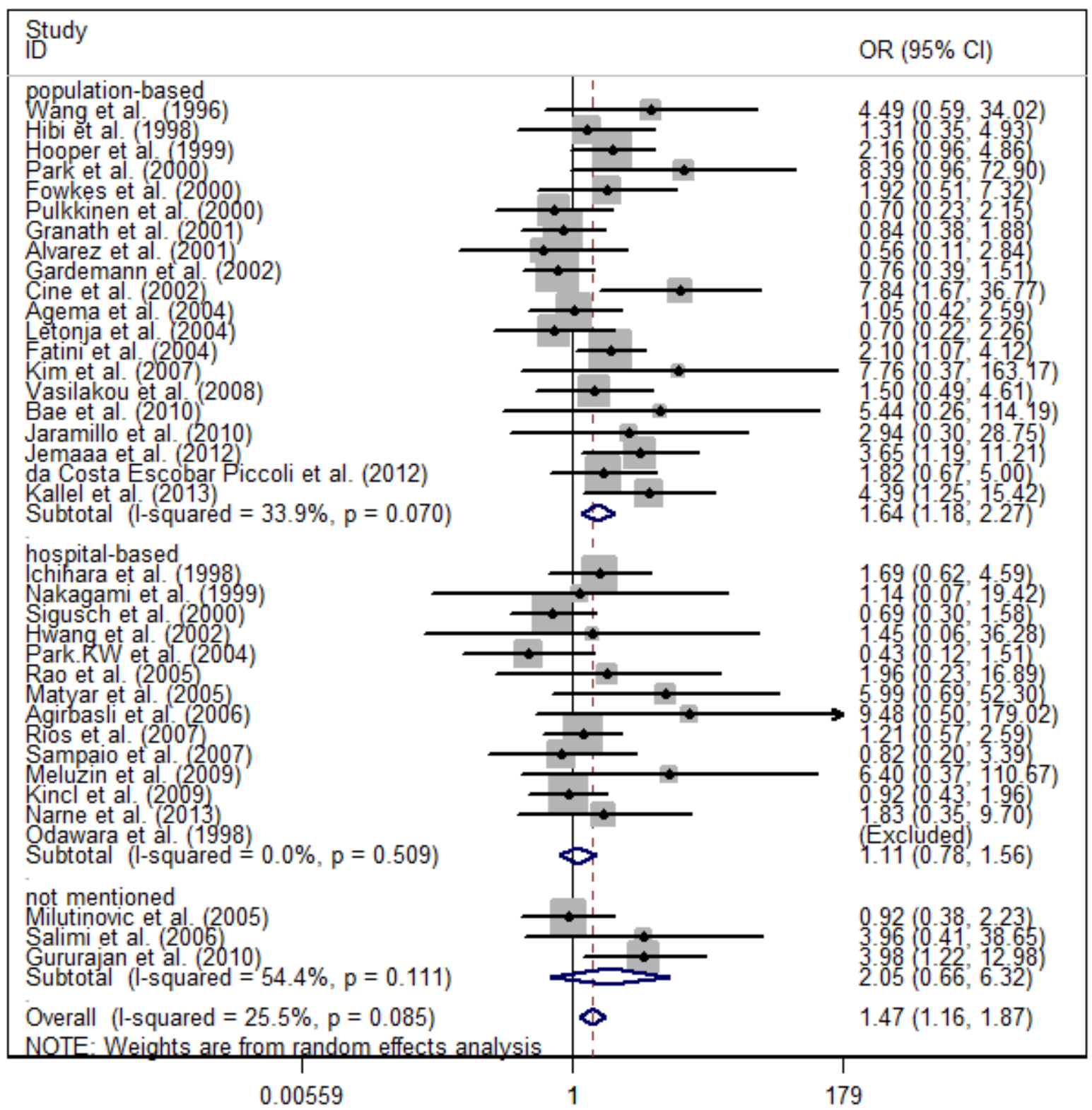

The data were also stratified into Asian and non-Asian subpopulations. There was a statistically significant association in the non-Asian subgroup in the homozygote comparison $(\mathrm{OR}=1.41$, $95 \% \mathrm{CI}=1.08-1.84, p=0.080)$ and the dominant model $(\mathrm{OR}=1.16,95 \% \mathrm{CI}=1.02-1.32, p<0.001)$. 
Non-Asians were then further stratified into Caucasians, Africans, and others. The populations of an American study and a Brazilian study were both composed of two ethnicities: Caucasians and Africans [39,40]. The different ethnic descents in these studies were considered to be two independent studies during sub-stratified analyses. Statistically significant associations were noted in African populations in three genetic models (homozygote comparison $\mathrm{OR}=2.93,95 \% \mathrm{CI}=1.71-5.03$, $p=0.821$; heterozygote comparison $\mathrm{OR}=1.46,95 \% \mathrm{CI}=1.16-1.83, p=0.353$; and the dominant model $\mathrm{OR}=1.58,95 \% \mathrm{CI}=1.27-1.96, p=0.370)$. Interestingly, significant associations were also found in Asian $(\mathrm{OR}=1.82,95 \% \mathrm{CI}=1.03-3.20, p=0.316)$ and "other" $(\mathrm{OR}=2.65,95 \% \mathrm{CI}=1.37-5.13$, $p=0.369)$ populations during the homozygote comparison. In contrast, no statistically significant associations were identified in Caucasian populations $(\mathrm{OR}=1.03,95 \% \mathrm{CI}=0.80-1.31, p=0.621$ in the homozygote comparison; $\mathrm{OR}=1.04,95 \% \mathrm{CI}=0.90-1.20, p=0.006$ in the heterozygote comparison; $\mathrm{OR}=1.04,95 \% \mathrm{CI}=0.91-1.19, p=0.007$ in the dominant model) (Supplementary Figure S1).

The data were then also stratified according to case sample size into large ( $>500$ total cases) and small-and-moderate case sample $(<500$ total cases) subgroups. Significant associations between eNOS $4 b / a$ polymorphisms and CAD risk were observed in the small-and-moderate case sample subgroup $(\mathrm{OR}=1.75,95 \% \mathrm{CI}=1.35-2.28, p=0.262$ in the homozygote comparison; $\mathrm{OR}=1.20$, $95 \% \mathrm{CI}=1.07-1.35, p=0.011$ in the heterozygote comparison; and $\mathrm{OR}=1.26,95 \% \mathrm{CI}=1.11-1.42$, $p=0.002$ in the dominant model) but not in the large case sample subgroup. The data were then stratified into large control ( $>500$ control individuals) and small-and-moderate control sample ( $<500$ control individuals) subgroups. Similar to the data from the case sample size analyses, significant associations were observed in the small-and-moderate control sample subgroup $(\mathrm{OR}=1.56$, 95\% CI $=1.19-2.05, p=0.113$ for the homozygote comparison; $\mathrm{OR}=1.15,95 \% \mathrm{CI}=1.01-1.31$, $p<0.001$ for the heterozygote comparison; and $\mathrm{OR}=1.20,95 \% \mathrm{CI}=1.06-1.36, p<0.001$ in the dominant model), but not the large case sample subgroup.

Finally, a subgroup analysis for MI was performed. There were significant associations between eNOS $4 b / a$ polymorphisms and CAD risk with the homozygote comparison $(\mathrm{OR}=2.30$, $95 \% \mathrm{CI}=1.17-4.51, p=0.020)$, heterozygote comparison $(\mathrm{OR}=1.42,95 \% \mathrm{CI}=1.07-1.89, p=0.002)$, and dominant model $(\mathrm{OR}=1.50,95 \% \mathrm{CI}=1.09-2.07, p<0.001)$ in patients with $\mathrm{MI}$.

\subsection{Evaluation of Heterogeneity}

There was minor heterogeneity among studies in the recessive model $(a b+b b$ vs. $a a$, $p_{\text {heterogeneity }}=0.213, I^{2}=15.4 \%$ ), while the results of heterogeneity tests were significant in the other three genetic models ( $a a v s . b b, p_{\text {heterogeneity }}=0.085, I^{2}=25.5 \%$; $a b v s b b, p_{\text {heterogeneity }}<0.001, I^{2}=56.7 \%$; $a b+a a$ vs. $b b, p_{\text {heterogeneity }}<0.001, I^{2}=61.1 \%$ ). The random-effects models were used in all the four genetic models. Meta-regression analyses were then performed to evaluate the extent to which different variables explained the heterogeneity. The results revealed that the heterogeneity could be explained by case sample size $(p=0.015)$ and total sample size $(p=0.015)$ in the homozygote comparison. However, population ethnicity, year of publication, source of control population, total sample size, and outcome were not statistically correlated with heterogeneity $(p>0.05)$. 


\subsection{Sensitivity Analysis and Publication Bias}

Sensitivity analysis was performed by omitting one study at a time. No significant differences in the data were observed, indicating that the results were statistically reliable (Supplementary Figure S2). The publication bias of the studies was assessed by performing the Begg's funnel plot and Egger's test. There was no obvious publication bias in the heterozygote comparison ( $a b v s$. $b b$, Begg's test $p=0.754$, Egger's test $p=0.473)$, and the dominant model $(a b+a a$ vs. $b b$, Begg's test $p=0.619$, Egger's test $p=0.274)$. The shape of the funnel plot for the homozygote comparison appeared to be approximately asymmetrical, which was confirmed by the test results (aa vs. $b b$, Begg's test $p=0.022$, Egger's test $p=0.004)$. However, adjusting the model by the trim and fill method did not influence the conclusions $(\mathrm{OR}=1.23,95 \% \mathrm{CI}=1.02-1.48)$ (Figure 3$)$.

Figure 3. Begg's funnel plot of publication bias test (homozygote comparison). (a) Before trim and fill method; and (b) After trim and fill method.

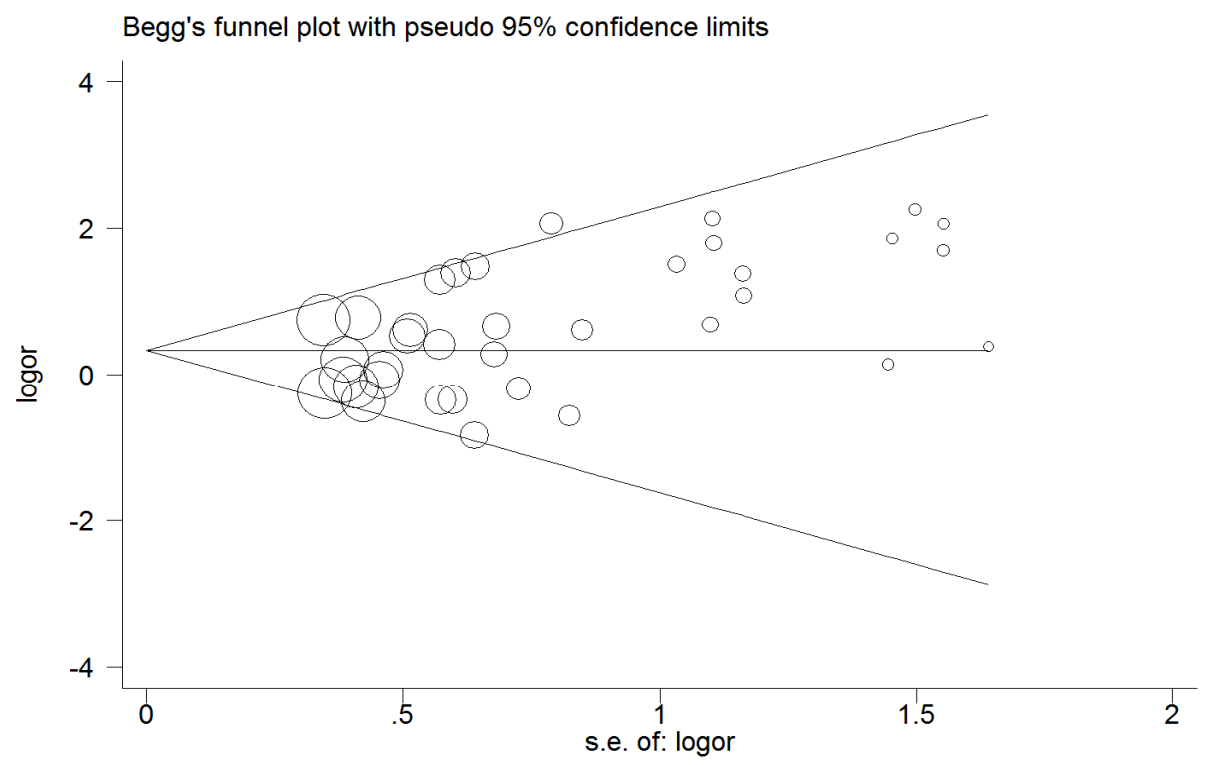

(a)

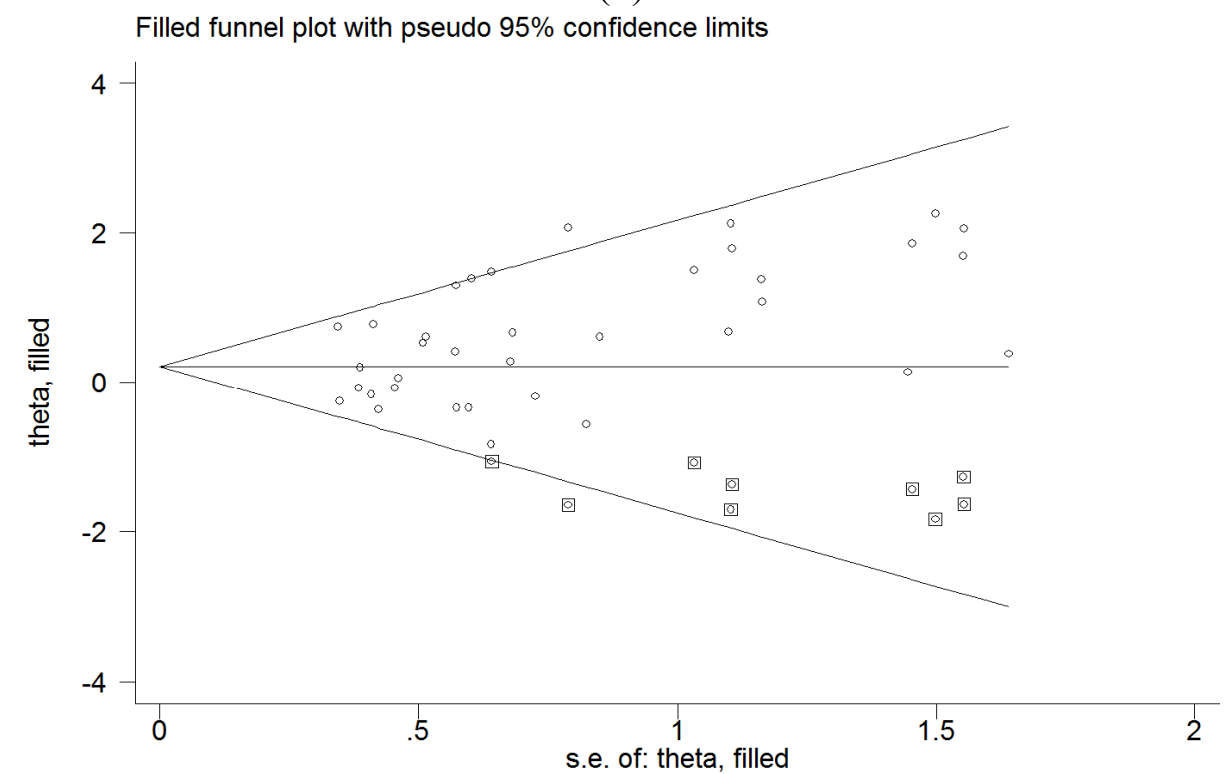

(b) 


\subsection{Discussion}

The meta-analysis revealed that eNOS $4 b / a$ polymorphisms were significantly associated with CAD in three genetic models (dominant model, homozygote comparison, and heterozygote comparison). These data suggest that carriers of the $a$ allele of the eNOS $4 b / a$ gene might be predisposed to CAD. Heterogeneity was observed in these three models; however, subsequent meta-regression analyses revealed that case and total sample size could explain the heterogeneity. Subgroup analysis based on source of the control population revealed that population-based subgroups with the $a a$ or $a b$ genotypes had a significantly increased risk of CAD. In stratified analyses according to ethnicity, significantly increased risk was detected in the African subgroup with the $a a$ or $a b$ genotypes and the Asian subgroup with the $a a$ genotype. Positive associations were also identified in studies whose case or control sample size was $<500$ with the $a a$ or $a b$ genotypes. Similarly, significant associations were identified in studies with the $a a$ or $a b$ genotypes in a subgroup analysis according to MI.

In 1998, a Japanese study including 413 subjects reported that the plasma levels of mono-nitrogen oxides in the $a$ allele group $(31.2 \pm 2.00 \mu \mathrm{mol} / \mathrm{L})$ were significantly lower than in the $b$ allele group $(35.5 \pm 0.93 \mu \mathrm{mol} / \mathrm{L})$ [48]. Reduced plasma concentrations of nitrogen oxides (NO) in carriers of the $a$ allele were also identified in a study by Rittig et al. in a German population [49]. Prevailing experimental and clinical data suggest that decreased NO bioavailability accelerates the progression of atherosclerosis presumably through mechanisms such as platelet activation, vascular smooth muscle proliferation, leukocyte adhesion to the endothelium and increased vascular production of reactive oxygen species [50,51]. Therefore, it is possible that eNOS $4 b / a$ gene polymorphisms could contribute to CAD risk by decreasing NO production, which subsequently affects the development of CAD. However, because this variant is located in the intronic region, it is possible that it is in linkage disequilibrium with other functional variants in regulatory regions of the NOS gene. In 2002, Wang et al. demonstrated that the eNOS $4 a$ allele coordinated with the T-786C variant in the promoter region to regulate the transcriptional efficiency of eNOS in a haplotype-specific fashion [52]. In 2013, Narne et al. reported that the eNOS $4 b / a$ polymorphism affected the bioavailability and activity of NO via linkage disequilibrium with T-786C and G894T variants [25]. Consistent with these observations, our meta-analysis revealed that individuals carrying the eNOS $4 a$ allele had a higher CAD risk than subjects carrying the $4 b$ allele.

Our results also suggested that the $4 a$ allele might be a risk factor for CAD among population-based but not hospital-based subgroups. One explanation for this is that there were differences in the frequency of exposure to risk factors between hospital- and population-based studies. The use of hospital-based population might limit the general applicability of the data. Furthermore, the sample size and number of studies in the hospital-based group might not be sufficient to evaluate potential associations.

In the subgroup analysis according to ethnicity, an increased risk in $4 a$ carriers was identified among African and Asian populations but not Caucasians. The results could be explained by varying susceptibility of different ethnicities to the eNOS $4 b / a$ polymorphism among different ethnicities. Environmental characteristics might also contribute to this discrepancy.

Two previous meta-analyses assessing eNOS 4b/a and CAD risk have been performed. In 2004, one study reported an association between eNOS $4 a / a$ and ischemic heart disease compared with $e N O S 4 b / b[10]$. Although IHD and CAD have overlapping pathogeneses, they are different disease. A second meta-analysis performed in 2010 did not reveal any association between this eNOS genetic 
variant and CAD risk [11]; therefore, our results contradict this study. This could be explained by several reasons. First, different inclusion and exclusion criteria were used. We excluded four studies in which the control population deviated from Hardy-Weinberg equilibrium (HWE) [53-56]. We also incorporated novel data published between 2010 and October 2013 in our study. Therefore, the number and content of the studies included by Li et al. and in the current meta-analysis differed. Second, we performed overall analyses in four genetic models; in contrast Li et al. did not perform homozygote comparison and heterozygote comparisons. We also performed subgroup analysis based on ethnicity, the source of the control population, and case sample size to identify all possible associations between $4 b / a$ polymorphisms and CAD; these factors were not investigated previously.

The present study has some limitations. First, heterogeneity was detected in three genetic models, suggesting that results should be interpreted with caution. Second, most of the included studies were case-control studies, where the cases were survivors of cardiovascular events; those who did not survive were not enrolled. Finally, the sample size in the studies was inadequate. The insufficient sample size might increase the probability of false positives or false negatives.

\section{Experimental Section}

\subsection{Literature Search}

We systematically searched PubMed using the following medical subject headings (MeSH) or search terms: "CHD" OR "atherosclerosis" OR "coronary atherosclerosis" OR "aortic atherosclerosis" OR "coronary heart disease" OR "coronary artery disease" OR "coronary disease" OR "myocardial infarction" OR "MI" OR "acute coronary syndrome") and ("polymorphism*” OR "variation") and ("eNOS" OR "endothelial nitric oxide synthase"). The search covered all English language publications within a range of published years from 1996 to 2013 (the last search was performed on 31 October 2013). The bibliographies of previous meta-analyses and published reviews were also checked for additional relevant publications.

\subsection{Inclusion and Exclusion Criteria}

The inclusion criteria for studies were as follows: (1) independent case-control, cohort or cross-sectional studies; (2) studies that evaluated the association between eNOS intron $4 b / a$ variable number of tandem repeats (VNTR) polymorphisms and CAD susceptibility; (3) studies that provided complete data regarding genotype number and allele frequencies; (4) studies in which CAD was diagnosed based on coronary angiography as well as clinical criteria with clearly reported details; (5) studies that also included controls demonstrated to lack CAD either by coronary arteriography or by clinical criteria; and (6) studies that were published in English. The exclusion criteria were as follows: (1) insufficient data regarding genotypes and allele frequencies; (2) unconfirmed diagnosis of CAD; (3) the genotype distribution of the control population did not conform to HWE; and (4) overlapping publications. 


\subsection{Data Extraction}

Two researchers (Y.Y. and K.D.) extracted information including the first author, year of publication, country, ethnicity of the study population, source of controls, genotype number in cases and controls, HWE in controls and study outcome. Data were extracted separately and compared to reach a consensus. Different ethnicities were categorized as Asians and non-Asians (Caucasians, Africans, or others). Different ethnic descents in one study were considered to be independent studies when subanalyses based on ethnicity were performed.

\subsection{Statistical Analysis}

The association between eNOS $4 b / a$ gene polymorphisms and CAD was compared using the odds ratio (OR) corresponding to a 95\% confidence interval $(95 \% \mathrm{CI})$. We used four different genetic models in our analysis: homozygote comparison ( $a a v s$. $b b)$, heterozygote comparison $(a b v s$. $b b)$, dominant $(a a+a b v s . b b)$, and recessive models $(a a v s . a b+b b)$.

Heterogeneity between studies was assessed using $p$ values for the $\mathrm{Q}$ statistic and $I^{2}$ values. Significance was set at the $p<0.1$ level; $p<0.1$ for the Q test indicated there was heterogeneity across the studies and $p>0.1$ for the $Q$ test indicated a lack of heterogeneity among studies. The random-effects model was used to estimate the pooled OR according to the DerSimonian and Laird method [57]. $I^{2}$ was calculated to describe the percentage of variation caused by the heterogeneity: $0 \%-25 \%$, no heterogeneity; $25 \%-50 \%$, moderate heterogeneity; $50 \%-75 \%$, large heterogeneity; and $75 \%-100 \%$, extreme heterogeneity).

To determine the source of heterogeneity across studies, logistic meta-regression analyses were performed. Publication year, population ethnicity, source of the control group, outcome, total sample size, case sample size, control sample size, and the ratio of case size to control size were examined to evaluate the extent to which different variables explained any observed heterogeneity. Stratified analyses were also performed for ethnicity, source of controls, and case sample size. Sensitivity analyses were conducted by removing each study individually and consecutively from the combined data set. Re-analysis of the remaining studies, allowed the robustness of the main findings to be tested. In addition, a funnel plot was used to estimate the potential publication bias; Begg's and Egger's tests were then used to examine funnel plot asymmetry with significance set at $p<0.05$, and the trim and fill method was performed when bias was detected. STATA 12.0 software was used to perform all statistical analyses (StataCorp, College Station, TX, USA).

\section{Conclusions}

In conclusion, the results of the current meta-analysis suggested that eNOS $4 b / a$ polymorphisms could increase the risk of CAD, particularly in African populations and among the population-based studies. Further studies with larger sample sizes should be performed to confirm these findings.

\section{Acknowledgments}

Grants from the Natural Science Foundation of China (No.81270428) supported this study. 


\section{Conflicts of Interest}

The authors declare no conflict of interest.

\section{References}

1. Gouvinhas, C.; Severo, M.; Azevedo, A.; Lunet, N. Worldwide patterns of ischemic heart disease mortality from 1980 to 2010. Int. J. Cardiol. 2013, 170, 309-314.

2. Salomon, J.A.; Vos, T.; Hogan, D.R.; Gagnon, M.; Naghavi, M.; Mokdad, A.; Begum, N.; Shah, R.; Karyana, M.; Kosen, S.; et al. Common values in assessing health outcomes from disease and injury: Disability weights measurement study for the global burden of disease study 2010. Lancet 2012, 380, 2129-2143.

3. Prins, B.P.; Lagou, V.; Asselbergs, F.W.; Snieder, H.; Fu, J. Genetics of coronary artery disease: Genome-wide association studies and beyond. Atherosclerosis 2012, 225, 1-10.

4. Smith, F.B.; Lee, A.J.; Fowkes, F.G.; Price, J.F.; Rumley, A.; Lowe, G.D. Hemostatic factors as predictors of ischemic heart disease and stroke in the Edinburgh artery study. Arterioscler. Thromb. Vasc. Biol. 1997, 17, 3321-3325.

5. Kraus, W.E. Genetic approaches for the investigation of genes associated with coronary heart disease. Am. Heart J. 2000, 140, S27-S35.

6. Kugiyama, K.; Yasue, H.; Okumura, K.; Ogawa, H.; Fujimoto, K.; Nakao, K.; Yoshimura, M.; Motoyama, T.; Inobe, Y.; Kawano, H. Nitric oxide activity is deficient in spasm arteries of patients with coronary spastic angina. Circulation 1996, 94, 266-271.

7. Nathan, C.; Xie, Q.W. Nitric oxide synthases: Roles, tolls, and controls. Cell 1994, 78, 915-918.

8. Marsden, P.A.; Heng, H.H.; Scherer, S.W.; Stewart, R.J.; Hall, A.V.; Shi, X.M.; Tsui, L.C.; Schappert, K.T. Structure and chromosomal localization of the human constitutive endothelial nitric oxide synthase gene. J. Biol. Chem. 1993, 268, 17478-17488.

9. Wang, X.L.; Sim, A.S.; Badenhop, R.F.; McCredie, R.M.; Wilcken, D.E. A smoking-dependent risk of coronary artery disease associated with a polymorphism of the endothelial nitric oxide synthase gene. Nat. Med. 1996, 2, 41-45.

10. Casas, J.P.; Bautista, L.E.; Humphries, S.E.; Hingorani, A.D. Endothelial nitric oxide synthase genotype and ischemic heart disease: Meta-analysis of 26 studies involving 23028 subjects. Circulation 2004, 109, 1359-1365.

11. Li, J.; Wu, X.; Li, X.; Feng, G.; He, L.; Shi, Y. The endothelial nitric oxide synthase gene is associated with coronary artery disease: A meta-analysis. Cardiology 2010, 116, 271-278.

12. Hooper, W.C.; Lally, C.; Austin, H.; Benson, J.; Dilley, A.; Wenger, N.K.; Whitsett, C.; Rawlins, P.; Evatt, B.L. The relationship between polymorphisms in the endothelial cell nitric oxide synthase gene and the platelet gpiiia gene with myocardial infarction and venous thromboembolism in African Americans. Chest 1999, 116, 880-886.

13. Kallel, A.; Sbai, M.H.; Sediri, Y.; Abdessalem, S.; Mourali, M.S.; Feki, M.; Mechmeche, R.; Jemaa, R.; Kaabachi, N. Polymorphisms of the NOS3 gene and risk of myocardial infarction in the Tunisian population. Cytokine 2013, 64, 646-651. 
14. Jemaa, R.; Kallel, A.; Sediri, Y.; Abdessalem, S.; Mourali, M.S.; Feki, M.; Mechmeche, R.; Kaabachi, N. Association between endothelial nitric oxide gene intron 4a 4b VNTR polymorphism and plasma homocysteine concentrations in Tunisian male patients with myocardial infarction. Nutr. Res. 2012, 32, 342-346.

15. Hibi, K.; Ishigami, T.; Tamura, K.; Mizushima, S.; Nyui, N.; Fujita, T.; Ochiai, H.; Kosuge, M.; Watanabe, Y.; Yoshii, Y.; et al. Endothelial nitric oxide synthase gene polymorphism and acute myocardial infarction. Hypertension 1998, 32, 521-526.

16. Ichihara, S.; Yamada, Y.; Fujimura, T.; Nakashima, N.; Yokota, M. Association of a polymorphism of the endothelial constitutive nitric oxide synthase gene with myocardial infarction in the Japanese population. Am. J. Cardiol. 1998, 81, 83-86.

17. Odawara, M.; Sasaki, K.; Tachi, Y.; Yamashita, K. Endothelial nitric oxide synthase gene polymorphism and coronary heart disease in Japanese NIDDM. Diabetologia 1998, 41, 365-366.

18. Nakagami, H.; Ikeda, U.; Maeda, Y.; Yamamoto, K.; Hojo, Y.; Kario, K.; Kuroki, S.; Shimada, K. Coronary artery disease and endothelial nitric oxide synthase and angiotensin-converting enzyme gene polymorphisms. J. Thromb. Thrombolysis 1999, 8, 191-195.

19. Park, J.E.; Lee, W.H.; Hwang, T.H.; Chu, J.A.; Kim, S.; Choi, Y.H.; Kim, J.S.; Kim, D.K.; Lee, S.H.; Hong, K.P.; et al. Aging affects the association between endothelial nitric oxide synthase gene polymorphism and acute myocardial infarction in the Korean male population. Korean $J$. Intern. Med. 2000, 15, 65-70.

20. Hwang, J.J.; Tsai, C.T.; Yeh, H.M.; Chiang, F.T.; Hsu, K.L.; Tseng, C.D.; Liau, C.S.; Tseng, Y.Z.; Lai, L.P. The 27-bp tandem repeat polymorphism in intron 4 of the endothelial nitric oxide synthase gene is not associated with coronary artery disease in a hospital-based Taiwanese population. Cardiology 2002, 97, 67-72.

21. Park, K.W.; You, K.H.; Oh, S.; Chae, I.H.; Kim, H.S.; Oh, B.H.; Lee, M.M.; Park, Y.B. Association of endothelial constitutive nitric oxide synthase gene polymorphism with acute coronary syndrome in Koreans. Heart 2004, 90, 282-285.

22. Kim, I.J.; Bae, J.; Lim, S.W.; Cha, D.H.; Cho, H.J.; Kim, S.; Yang, D.H.; Hwang, S.G.; Oh, D.; Kim, N.K. Influence of endothelial nitric oxide synthase gene polymorphisms $(-786 \mathrm{~T}>\mathrm{C}, 4 \mathrm{a} 4 \mathrm{~b}$, 894G>T) in Korean patients with coronary artery disease. Thromb. Res. 2007, 119, 579-585.

23. Bae, J.; Kim, I.J.; Hong, S.H.; Sung, J.H.; Lim, S.W.; Cha, D.H.; Cho, Y.W.; Oh, D.; Kim, N.K. Association of endothelial nitric oxide synthase polymorphisms with coronary artery disease in Korean individuals with or without diabetes mellitus. Exp. Ther. Med. 2010, 1, 719-724.

24. Gururajan, P.; Gurumurthy, P.; Victor, D.; Rao, G.S.N.; Babu, R.S.; Bharati, A.S.; Cherian, K.M. Plasma total nitric oxide and endothelial constitutive nitric oxide synthase (ecNOS) gene polymorphism: A study in a South Indian population. Biochem. Genet. 2011, 49, 96-103.

25. Narne, P.; Ponnaluri, K.C.; Singh, S.; Siraj, M.; Ishaq, M. Association of the genetic variants of endothelial nitric oxide synthase gene with angiographically defined coronary artery disease and myocardial infarction in south Indian patients with type 2 diabetes mellitus. J. Diabetes Complicat. 2013, 27, 255-261. 
26. Fowkes, F.G.; Lee, A.J.; Hau, C.M.; Cooke, A.; Connor, J.M.; Lowe, G.D. Methylene tetrahydrofolate reductase (MTHFR) and nitric oxide synthase (ecNOS) genes and risks of peripheral arterial disease and coronary heart disease: Edinburgh artery study. Atherosclerosis 2000, 150, 179-185.

27. Pulkkinen, A.; Viitanen, L.; Kareinen, A.; Lehto, S.; Vauhkonen, I.; Laakso, M. Intron 4 polymorphism of the endothelial nitric oxide synthase gene is associated with elevated blood pressure in type 2 diabetic patients with coronary heart disease. J. Mol. Med. 2000, 78, 372-379.

28. Sigusch, H.H.; Surber, R.; Lehmann, M.H.; Surber, S.; Weber, J.; Henke, A.; Reinhardt, D.; Hoffmann, A.; Figulla, H.R. Lack of association between 27-bp repeat polymorphism in intron 4 of the endothelial nitric oxide synthase gene and the risk of coronary artery disease. Scand. J. Clin. Lab. Investig. 2000, 60, 229-235.

29. Alvarez, R.; Gonzalez, P.; Batalla, A.; Reguero, J.R.; Iglesias-Cubero, G.; Hevia, S.; Cortina, A.; Merino, E.; Gonzalez, I.; Alvarez, V.; et al. Association between the NOS3 (-786 T/C) and the ACE (I/D) DNA genotypes and early coronary artery disease. Nitric Oxide 2001, 5, 343-348.

30. Granath, B.; Taylor, R.R.; van Bockxmeer, F.M.; Mamotte, C.D. Lack of evidence for association between endothelial nitric oxide synthase gene polymorphisms and coronary artery disease in the Australian Caucasian population. Eur. J. Prev. Cardiol. 2001, 8, 235-241.

31. Gardemann, A.; Lohre, J.; Cayci, S.; Katz, N.; Tillmanns, H.; Haberbosch, W. The T allele of the missense $\mathrm{Glu}_{298} \mathrm{Asp}$ endothelial nitric oxide synthase gene polymorphism is associated with coronary heart disease in younger individuals with high atherosclerotic risk profile. Atherosclerosis 2002, 160, 167-175.

32. Agema, W.R.; de Maat, M.P.; Zwinderman, A.H.; Kastelein, J.J.; Rabelink, T.J.; van Boven, A.J.; Feskens, E.J.; Boer, J.M.; van der Wall, E.E.; Jukema, J.W. An integrated evaluation of endothelial constitutive nitric oxide synthase polymorphisms and coronary artery disease in men. Clin. Sci. 2004, 107, 255-261.

33. Fatini, C.; Sofi, F.; Sticchi, E.; Gensini, F.; Gori, A.M.; Fedi, S.; Lapini, I.; Rostagno, C.; Comeglio, M.; Brogi, D.; et al. Influence of endothelial nitric oxide synthase gene polymorphisms (G894T, 4a4b, T-786C) and hyperhomocysteinemia on the predisposition to acute coronary syndromes. Am. Heart J. 2004, 147, 516-521.

34. Letonja, M. The eNOS gene polymorphism does not have a major impact on lipid parameters and premature coronary artery disease in Caucasian women. Acta Cardiol. 2004, 59, 618-622.

35. Milutinovic, A.; Hruskovicova, H. The eNOS gene polymorphism does not have a major impact on lipid parameters and premature coronary artery disease in Slovene men (Caucasians). Folia Biol. 2005, 51, 47-49.

36. Vasilakou, M.; Votteas, V.; Kasparian, C.; Pantazopoulos, N.; Dedoussis, G.; Deltas, C.; Nastos, P.; Nikolakis, D.; Lamnissou, K. Lack of association between endothelial nitric oxide synthase gene polymorphisms and risk of premature coronary artery disease in the Greek population. Acta Cardiol. 2008, 63, 609-614.

37. Kincl, V.; Vasku, A.; Meluzin, J.; Panovsky, R.; Semenka, J.; Groch, L. Association of the eNOS $4 \mathrm{a} / \mathrm{b}$ and $-786 \mathrm{~T} / \mathrm{C}$ polymormphisms with coronary artery disease, obesity and diabetes mellitus. Folia Biol. 2009, 55, 187-191. 
38. Meluzin, J.; Vasku, A.; Kincl, V.; Panovsky, R.; Sramkova, T. Association of coronary artery disease, erectile dysfunction, and endothelial nitric oxide synthase polymorphisms. Heart Vessels 2009, 24, 157-163.

39. Rao, S.; Austin, H.; Davidoff, M.N.; Zafari, A.M. Endothelial nitric oxide synthase intron 4 polymorphism is a marker for coronary artery disease in African-American and Caucasian men. Ethn. Dis. 2005, 15, 191-197.

40. Rios, D.L.; D’Onofrio, L.O.; Souza, J.K.; Queiroz, A.M.; Raduy-Maron, L.; Silva-Neto, N.; Carvalho, H.G.; Santos-Filho, A.; Galvao-Castro, B. Smoking-dependent and haplotype-specific effects of endothelial nitric oxide synthase gene polymorphisms on angiographically assessed coronary artery disease in Caucasian- And african-Brazilians. Atherosclerosis 2007, 193, 135-141.

41. Cine, N.; Hatemi, A.C.; Erginel-Unaltuna, N. Association of a polymorphism of the ecNOS gene with myocardial infarction in a subgroup of Turkish MI patients. Clin. Genet. 2002, 61, 66-70.

42. Matyar, S.; Attila, G.; Acarturk, E.; Akpinar, O.; Inal, T. eNOS gene intron 4 a/b VNTR polymorphism is a risk factor for coronary artery disease in Southern Turkey. Clin. Chim. Acta 2005, 354, 153-158.

43. Agirbasli, D.; Agirbasli, M.; Williams, S.M.; Phillips, J.A., III. Interaction among 5,10 methylenetetrahydrofolate reductase, plasminogen activator inhibitor and endothelial nitric oxide synthase gene polymorphisms predicts the severity of coronary artery disease in Turkish patients. Coron. Artery Dis. 2006, 17, 413-417.

44. Salimi, S.; Firoozrai, M.; Nourmohammadi, I.; Shabani, M.; Mohebbi, A. Endothelial nitric oxide synthase gene intron4 VNTR polymorphism in patients with coronary artery disease in Iran. Indian J. Med. Res. 2006, 124, 683-688.

45. Sampaio, M.F.; Hirata, M.H.; Hirata, R.D.; Santos, F.C.; Picciotti, R.; Luchessi, A.D.; de Quateli Doi, S.; Armaganijan, D.; Batlouni, M. AMI is associated with polymorphisms in the NOS3 and FGB but not in PAI-1 genes in young adults. Clin. Chim. Acta 2007, 377, 154-162.

46. Jaramillo, P.C.; Lanas, C.; Lanas, F.; Salazar, L.A. Polymorphisms of the NOS3 gene in Southern Chilean subjects with coronary artery disease and controls. Clin. Chim. Acta 2010, 411, 258-262.

47. Da Costa Escobar Piccoli, J.; Manfredini, V.; Hamester, F.I.; Bandinelli, J.B.; Turkienicz, I.M.; Chies, J.A.; Peres, A.; Bodanese, L.C.; Bogo, M.R. Interaction between endothelial nitric oxide synthase gene polymorphisms $(-786 \mathrm{~T}>\mathrm{C}, 894 \mathrm{G}>\mathrm{T}$ and intron $4 \mathrm{a} / \mathrm{b})$ and cardiovascular risk factors in acute coronary syndromes. Arch. Med. Res. 2012, 43, 205-211.

48. Tsukada, T.; Yokoyama, K.; Arai, T.; Takemoto, F.; Hara, S.; Yamada, A.; Kawaguchi, Y.; Hosoya, T.; Igari, J. Evidence of association of the ecNOS gene polymorphism with plasma no metabolite levels in humans. Biochem. Biophys. Res. Commun. 1998, 245, 190-193.

49. Rittig, K.; Holder, K.; Stock, J.; Tschritter, O.; Peter, A.; Stefan, N.; Fritsche, A.; Machicao, F.; Haring, H.U.; Balletshofer, B. Endothelial no-synthase intron 4 polymorphism is associated with disturbed in vivo nitric oxide production in individuals prone to type 2 diabetes. Horm. Metab. Res. 2008, 40, 13-17.

50. Kojda, G.; Harrison, D. Interactions between no and reactive oxygen species: Pathophysiological importance in atherosclerosis, hypertension, diabetes and heart failure. Cardiovasc. Res. 1999, 43, $562-571$. 
51. Skovgaard, N.; Galli, G.; Abe, A.; Taylor, E.W.; Wang, T. The role of nitric oxide in regulation of the cardiovascular system in reptiles. Comp. Biochem. Physiol. A Mol. Integr. Physiol. 2005, 142, 205-214.

52. Wang, J.; Dudley, D.; Wang, X.L. Haplotype-specific effects on endothelial no synthase promoter efficiency: Modifiable by cigarette smoking. Arteriosclerosis 2002, 22, e1-e4.

53. Yoon, Y.; Song, J.; Hong, S.H.; Kim, J.Q. Plasma nitric oxide concentrations and nitric oxide synthase gene polymorphisms in coronary artery disease. Clin. Chem. 2000, 46, 1626-1630.

54. Lee, W.H.; Hwang, T.H.; Oh, G.T.; Kwon, S.U.; Choi, Y.H.; Park, J.E. Genetic factors associated with endothelial dysfunction affect the early onset of coronary artery disease in Korean males. Vasc. Med. 2001, 6, 103-108.

55. Angeline, T.; Isabel, W.; Tsongalis, G.J. Endothelial nitric oxide gene polymorphisms, nitric oxide production and coronary artery disease risk in a South Indian population. Exp. Mol. Pathol. 2010, 89, 205-208.

56. Syed, R.; Biyabani, M.U.; Prasad, S.; Deeba, F.; Jamil, K. Correlation and identification of variable number of tandem repeats of eNOS gene in coronary artery disease (CAD). Saudi J. Biol. Sci. 2010, 17, 209-213.

57. DerSimonian, R.; Laird, N. Meta-analysis in clinical trials. Control. Clin. Trials 1986, 7, 177-188.

(C) 2014 by the authors; licensee MDPI, Basel, Switzerland. This article is an open access article distributed under the terms and conditions of the Creative Commons Attribution license (http://creativecommons.org/licenses/by/3.0/). 